\title{
TECNOLOGIAS DE INFORMAÇÃO E COMUNICAÇÃO NA FORMAÇÃO DE PROFESSORES
}

\author{
Rosana Maria Luvezute Kripka \\ Universidade de Passo Fundo (UPF) \\ Pontifícia Universidade Católica do Rio Grande do Sul (PUCRS) \\ E-mail: rkripka@upf.br
}

\section{Lori Viali, Regis Alexandre Lahm}

Pontifícia Universidade Católica do Rio Grande do Sul (PUCRS)

Universidade Federal do Rio Grande do Sul (UFRGS)

E-mail: viali@pucrs.br, lahm@pucrs.br

Resumo: Com objetivo de identificar atuais desafios e possibilidades em contextos educacionais, realizou-se um estudo teórico sobre processos de formação de professores e uso de tecnologias da Informação e Comunicação (TIC). Identificou-se que são necessárias transformações estruturais em processos formativos de modo a inserir os recursos das TIC nos ambientes formais de ensino. Esse processo se inicia com a promoção de reflexões que possibilitem perceber a necessidade de inovações em práticas. Prossegue com a proposição de inovações que propiciem a inserção do uso de recursos tecnológicos em ambientes de aprendizagem, visando a aproximação do ambiente escolar à realidade vivenciada pelos estudantes, onde os usos de recursos tecnológicos devem ser entendidos como mediadores em atividades de construção do conhecimento. Conclui-se que talvez seja esse maior desafio da educação, na atualidade: formar professores capazes de explorar os recursos tecnológicos que favoreçam a aprendizagem, de modo a potencializar a formação integral do estudante.

Palavras-chave: formação de professores, TIC, recursos tecnológicos, ensino e aprendizagem.

\section{TEACHER TRAINING AND ICT USE: CHALLENGES AND POSSIBILITIES}

Abstract: Aiming to identify current challenges and opportunities in educational contexts, we conducted a theoretical study on teacher training processes and use of Information and Communication Technologies (ICT). It was identified that are necessary structural changes in training processes in order to insert the resources of ICT in formal education environments. This process begins with the promotion of reflections that allow to realize the need for innovations in practice. Proceeds with the proposition of innovations that facilitate the insertion of the use of technological resources in learning environments, aiming to approach the school environment to the reality experienced by students, where technological resource uses must be understood as mediators in knowledge building activities. It concludes that maybe this greatest challenge of education today: train teachers able to exploit the technological resources that support learning in order to enhance the integral formation of the student.

Keywords: teacher training, ICT, technological resources, teaching and learning.

Recebido em 30/09/2015. Publicado em 30/03/2016. 


\section{INTRODUÇÃO}

Muitos contextos consideram a racionalidade técnica como o único modo de construção do conhecimento válido, devido ao prestígio das Ciências Empírico - Analíticas no decorrer da história. Isto pode ser muito prejudicial aos objetivos de uma educação democrática e transformadora, sendo inclusive contraproducente para uma sociedade como um todo (WELLS, 2001).

No entanto, as mudanças sociais e culturais têm contribuído com o fracasso do ensino escolar tradicional. Apesar disso, muitos professores ainda assumem como prática docente a aula meramente expositiva, assumindo que apenas a "transmissão de informações" é suficiente para que possa ocorrer a aprendizagem, acreditando que o estudante possa desta forma, construir seus próprios conhecimentos.

Perrenoud (1999, p. 1) ressalta:

As sociedades se transformam, fazem-se e desfazem-se. As tecnologias mudam o trabalho, a comunicação, a vida cotidiana e mesmo o pensamento. As desigualdades se deslocam, agravam-se e recriam-se em novos territórios. Os atores estão ligados a múltiplos campos sociais, a modernidade não permite a ninguém proteger-se das contradições do mundo. Quais as lições que daí podem ser tiradas para a formação de professores? Certamente, convém reforçar sua preparação para uma prática reflexiva' para a inovação e a cooperação.

Nóvoa (2009b, p. 205) afirma que:

A educação vive um tempo de grandes incertezas e de muitas perplexidades. Sentimos a necessidade de mudar, mas nem sempre conseguimos definir seu curso. Existe um excesso de discursos, redundantes e repetitivos, que se traduz na pobreza das práticas.

O autor indica que é necessário propiciar a construção da formação de professores, de modo que as práticas devam estar fortemente presentes no processo. Indica que a formação deve estar centrada na aprendizagem do aluno e no estudo de problemas concretos, visando relacionar teoria estudada e prática, além da reflexão e da construção de conhecimento por meio do 
desenvolvimento de processos investigativos colaborativos. Também salienta a importância de serem trabalhadas dimensões pessoais dos professores, como capacidade de relacionar-se e de comunicação, tão importantes em relações entre professores e alunos. Sugere que, para se identificar um bom professor é necessário reconhecer: "[...] conhecimento, cultura profissional, tato profissional, trabalho em equipe e compromisso social" (NÓVOA, 2009b, p. 216).

Segundo orientações de documentos brasileiros, a formação continuada deve promover:

[...] continuamente o desenvolvimento de competências que possibilitam uma atuação pautada não apenas na função docente, mas também na condição de membro de uma equipe responsável pela formulação, implementação e avaliação do projeto educativo da escola e membro de uma categoria profissional (BRASIL, 2002, p.131).

Dessa forma, constata-se a necessidade de promover uma formação continuada que possibilite aos professores reflexões críticas acerca de suas atuações em ambientes educacionais, que vise propiciar o reconhecimento da necessidade de mudança profissional frente aos novos contextos educacionais e que estimule os professores a proporem e atuarem com segurança e competência no desenvolvimento de práticas inovadoras.

Nóvoa (2009a) ao apresentar contextos históricos que definem momentos de transição quanto aos rumos da educação e indica sugestões de como deveria ser a educação do futuro. Ao abordar questões sobre a transição da escola do passado para a escola do futuro, salienta a importância das novas tecnologias por possibilitarem o aprendizado individualizado, em qualquer tempo e a qualquer hora, com professores reais ou individuais. Além disso, afirma que diversos autores defendem que as tecnologias seriam as chaves para a escola do futuro. O autor sugere que as escolas que conhecemos deixarão de existir e passarão a existir centros de aprendizagem e ressalta a importância de refletirmos sobre essa necessidade de mudança nos espaços de aprendizagem.

Além disso, segundo Borba e Penteado (2003, p. 65):

A escola, sobretudo a sala de aula, não é fonte exclusiva de informações para os alunos. Atualmente as informações podem ser obtidas nos mais variados lugares. Porém, sabemos que informação não é tudo, é preciso um espaço em que elas 
Kripka, Viali e Lahm, 2016 - Formação de Professores

sejam organizadas e discutidas. A escola pode ser esse tal espaço. Um espaço pensado como se fosse uma "mesa" onde alunos e professores se sentam para compartilhar as diferentes informações e experiências vividas, gerar e disseminar novos conhecimentos. O professor pode vir a perceber que cabe a ele compartilhar com seus alunos a responsabilidade pela organização dessa mesa de modo a constituí-la num ambiente de aprendizagem e geração de novos conhecimentos.

Diante das mudanças referentes aos avanços tecnológicos, que na atualidade são tão significativas ao longo da história e da sociedade, propõe-se neste artigo identificar quais seriam os desafios e possibilidades que se apresentam para a formação de professores na sociedade contemporânea e de que modo as TIC podem contribuir neste processo? Entre as diversas referências consultadas, foram escolhidas aquelas que possibilitaram relacionar dificuldades e potencialidades reconhecidas em processos de formação de professores atuais, bem como possibilidades de contribuições do uso de recursos das TIC em contextos educacionais contemporâneos.

\section{DESAFIOS E POSSIBILIDADES}

Muitos pesquisadores tem se dedicado a responder tais questões e existem diversas teorias de ensino e aprendizagem que buscam superar tais dificuldades.

Wells (2001), opondo-se ao ensino tradicional, apresenta uma proposta alternativa para o ensino, na qual considera ideias de Halliday e Vygotsky, que trabalham com a perspectiva da interação construtivista social, indicando que a construção do conhecimento possui natureza essencialmente construtivista e dialógica. Propõe reflexões sobre a natureza do conhecimento e da forma como se dá seu desenvolvimento. Salienta que o principal objetivo da educação é a compreensão, que se alcança mediante o estímulo, em atividades de conhecer, que devem ser de investigação, colaborativas, interessantes e desafiadoras. Indica que estas são mediadas por artefatos de representação, guiando a ação conjunta na construção do conhecimento. Para romper com o processo tradicional de ensino, que considera o conhecer como uma reestruturação superficial da informação, o autor sugere realizar um trabalho dialógico em sala de aula, começando por perguntas reais, para identificar problemas que gerem interesse genuíno nos estudantes. Acredita que, enquanto não tiver interesse pessoal no conhecimento que se constrói é 
provável que apenas sejam considerados escritos publicados por outras pessoas, o que exclui a necessidade de realizar esforço construtivo da parte do aluno.

Na proposta de Wells (2001), o fato das atividades de construção de conhecimentos, propostas pelo professor serem mediadas por artefatos de representação remete ao aspecto mediador das TIC ressaltados por Lèvy (1993), na interação do indivíduo com o meio e na construção do conhecimento. Nesse o formador deve ser animador da inteligência coletiva, estimulando a troca de saberes, a mediação relacional e simbólica, sendo o condutor dos percursos da aprendizagem, o que indica uma possibilidade e um desafio.

Wells (2001) também relata que uma das principais afirmações de Halliday e Vygotsky em relação à Teoria da Aprendizagem baseada na linguagem é que, na construção do conhecimento, a linguagem oferece um meio essencial para a aprendizagem.

Pretto (1996) ao defender a inserção das TIC na prática pedagógica como fundamento que possibilita aprendizagem indica a necessidade da inclusão da linguagem digital ao lado da oral e da escrita, que se também constitui uma possibilidade e outro desafio na formação de professores.

Kensky (2007) indica que na formação e professores é necessário o contato direto com as tecnologias e seus diferentes usos para o ensino, não apenas do ponto de vista teórico ou técnico, mas de forma que possibilite explorar o potencial pedagógico das propostas, para que o docente seja capaz de inserir novos recursos tecnológicos em sua prática. A formação deve possibilitar o contato com novas formas de ensinar e de aprender, acompanhando as constantes transformações da sociedade em que vivemos.

O mapeamento apresentado por Barreto et al. (2006) sobre as TIC na formação de professores buscou verificar o movimento de aproximação entre Educação e Tecnologias e identificar a frequência de elementos e relações nos documentos pesquisados. O estudo indica que pesquisas desenvolvidas em teses e dissertações visando o uso de recursos das Tecnologias da Informação e Comunicação (TIC) no Ensino tiveram um aumento significativo entre os anos de 1996 a 2002. Também indica que, os contextos de aplicação são de Ensino à Distância (EAD) e presencial, com modalidades de ensino presencial, virtual e à distância. Informam que tecnologia mais presente, e ascendente, seria o uso de informática, estando em segundo lugar o uso de programas de TV ou de vídeos, seguidos de TIC, de modo geral. 
Os autores também identificaram que o caráter interativo das novas tecnologias seria um dos fatores responsáveis por mudanças estruturais ocorridas nas formações de professores.

Nos trabalhos analisados também verificaram que os ambientes de aprendizagem se referem à: laboratório de informática, laboratório de EAD, espaço virtual, ambiente web, comunidade virtual, ciberespaço. Indicam que essa última expressão que sustenta a proposição de outros espaços de aprendizagem, na ruptura com o conceito físico e na constituição fora dos limites da sala de aula e da escola.

Segundo os autores, o mapeamento possibilitou identificar duas tendências, uma associada às modalidades de ensino, com ênfase na abordagem da formação de professores por meio da EAD e outra associada aos contextos de aplicação das TIC, em propostas da virtualização do ensino.

Ao analisar se existiam relações entre pesquisas relativas ao ensino presencial e às relativas ao ensino virtual ou em processo de virtualização, identificaram que em ambos os casos os pesquisadores afirmam existir um distanciamento entre escola e práticas sociais, indicando a necessidade de busca por aproximação. As pesquisas relativas ao ensino presencial propõem a incorporação das TIC em práticas pedagógicas, visando mudanças significativas, como processo de redimensionamento do ensino, não apenas contando com novas ferramentas ou instrumentos para a realização de sequências de ensino-aprendizagem. Já as pesquisas que defendem o ensino virtual discordam afirmando que estas mudanças encontrariam obstáculos no sistema regular. Os autores também identificaram que ambos os tipos de pesquisas abordam questões relativas à presença das resistências de professores no uso de TIC. Porém citam divergências. No caso de pesquisas relacionadas ao ensino presencial, os autores afirmam que as resistências se devem ao fato do uso das TIC serem impostas como soluções verticais ao problema do ensino e aprendizagem. Já no caso de pesquisas relativas ao ensino virtual, os autores afirmam que as TIC não podem produzir mudanças significativas na educação regular ante a orientação "instrucionista", ao serem incorporadas apenas como ferramentas para o ensino. No ensino presencial, os autores identificaram uma tendência a propostas de redimensionamento do ensino em instituições educativas regulares, com investimento na interação professor-aluno, visando o fortalecimento do binômio: ensino e aprendizagem. Quanto às propostas de virtualização do ensino as pesquisas apontam para um deslocamento da dimensão presencial para a virtual; onde se propõe uma nova relação educativa na comunidade virtual, estabelecida de "modo 
espontâneo", rompendo com a assimetria presente na escola, privilegiando apenas o segundo elemento do binômio ensino-aprendizagem, pensado como "autoaprendizagem".

Também identificaram que, quanto à incorporação das TIC no ensino, as pesquisas apontam para a produção de alternativas cada vez mais plurais e sofisticadas para múltiplos fins.

Nas teses e dissertações que propõem a virtualização do ensino, identificaram que os pesquisadores reivindicam outra "distância" da escola, ou seja, a dos padrões assimétricos de interação, afirmando que não se trata apenas uma questão de lugar e de meios, mas de outro fim. Sustentam outra concepção de educação, centrada na autoaprendizagem, com possibilidade de novos dispositivos pedagógicos, por meio da criação de redes comunicacionais de colaboração e cooperação, como forma de viabilizar novas práticas, remetendo a uma espécie de negação do ensino, em atitude coerente com a proposta globalmente considerada. Fundamentam-se em paradigma educacional emergente, no qual a tecnologia informática é concebida como propiciadora de novos regimes cognitivos, apontando para múltiplas possibilidades de aprendizagem, baseadas em movimentos espontâneos que parecem não caber no ensino, ante a intencionalidade da ação.

No mapeamento realizado, também identificaram que o Ensino à distância tende a ser mais formalizado, destituído de caráter espontaneísta associado a programas de estudo a serem cumpridos com disciplina, perseverança e atributos afins. No entanto, verificaram que esses limites tornam-se mais tênues por conta da crescente sofisticação tecnológica e da sua configuração discursiva.

Além disso, na literatura, também existem diversas pesquisas mais específicas, direcionadas à formação de professores que visam identificar necessidades de professores relacionadas à esses processos.

Martini e Bueno (2014) apresentam resultados de uma investigação realizada sobre desafios do uso de tecnologias na formação inicial de professores de matemática nas modalidades presencial e a distância. O autores concluíram que na modalidade presencial os recurso das TIC são mais usados para realização de exercícios extra classe e que na modalidade a distância, não prioriza a melhoria da qualidade do ensino, mas visa a comunicação e interação. Indicam que o uso das tecnologias somente será apropriada ao ambiente educacional caso seja incorporada de modo 
responsável, com intencionalidade crítica, de modo que propicie a participação de todos envolvidos. Salientam a importância do professor no processo de aprendizagem, que precisa rever suas práticas de modo a contribuir com os processos educativos. Também afirmam que consideram que as vivências com uso de tecnologias ao longo de processos de formações iniciais podem favorecer aos futuros professores na exploração desses recursos em suas práticas, as quais devem ser constantemente revistas e transformadas para se readequarem às inovações tecnológicas frequentes. Salientam que concordam com Perrenoud (2000) ao afirmar que formar professores para uso de tecnologias não se trata apenas de transmitir conceitos, técnicas ou de propiciar domínio de uso de diferentes ferramentas tecnológicas, mas que se trata de um processo complexo, que necessita de desenvolvimento de senso crítico, de formação de julgamento e de elaboração de novas estratégias de comunicação.

Algumas pesquisas indicam que o tópico: "exploração e uso adequado de tecnologias em modalidades presenciais ou não", aparecem como sugestões de professores como um tópico importante a ser contemplado em processos formativos, considerando as mudanças ocorridas na sociedade e na educação, devido à rápida evolução tecnológica que permeia e ultrapassa os muros da sala de aula e da escola.

Como exemplo, Souza e Ducatti-Silva (2012), ao apresentarem resultados de uma investigação direcionada à formação continuada de professores de matemática do ensino fundamental, na qual os professores eram estimulados para propor inovações em suas práticas por meio da participação ativa em projetos, ressaltam que os professores ao desenvolverem seus projetos para ensino e aprendizagem, indicam que "o uso de tecnologias como uma ferramenta educacional" se constitui numa necessidade atual na busca por práticas inovadoras, afirmando que isso se deve ao contexto dinâmico de transformação da sociedade contemporânea.

Também pode ser citado o trabalho de Oliveira (2011) apresenta uma pesquisa exploratória sobre formação continuada de professores de matemática, que visou identificar qual seria o "conjunto de saberes docentes que podem tornar os professores mais bem sucedidos e realizados nas tarefas que desenvolvem e predispostos à busca da formação contínua". Ao analisar os resultados identificou a importância do tema: "uso de TIC no ensino", identificado e destacado pelos professores que estavam participando dos processos de formação. Também verificou que os professores reconhecem a existência de políticas que preveem a formação de professores, mas que entendem 
que muitas não geram resultados esperados, pois não consideram o contexto social e psicológico dos professores e também por serem muito rápidas e de qualidade inferior ao que se julga necessário. Também indicam a necessidade do professor em adquirir uma sólida cultura geral, além de habilidades e de competências para articular suas aulas com as mídias e multimídias existentes.

A autora indica que a pesquisa possibilitou inferir três afirmativas: 1) é necessário formar professores que tenham em seu perfil o apreço pela inovação, ou seja, utilização das TIC e a própria rapidez com que elas evoluem, o que demanda do professor bastante adaptabilidade à busca do novo e à quebra das rotinas seculares; 2) para educar verdadeiramente os alunos e não apenas informatizá-los, o professor precisa aprender a conjugar o moderno e o tradicional, ou seja, é necessário que a formação docente não prepare os professores para uma desenfreada adesão às TIC, esquecendo que educar é um processo bastante mais amplo e complexo e 3) é necessário preparar o professor, ao mesmo tempo, para o uso das TIC, para as ações de mediação e para a interação ativa com os alunos. Como se trata da incorporação e da apropriação do uso das TIC há algumas especificidades que devem ser contempladas nas iniciativas de formação continuada.

Segundo Oliveira (2011), para o professor, integrar as TIC à sua prática significa incorporá-las em sua abordagem pedagógica: como conteúdo escolar integrante das várias disciplinas do currículo e como competências e atitudes profissionais; como meios tecnológicos de comunicação para ensinar a pensar e ensinar a aprender a aprender. Essa integração implica em efeitos didáticos como: desenvolvimento de pensamento autônomo; estratégias cognitivas; autonomia para organizar e dirigir seu próprio processo de aprendizagem e facilidade de análise e resolução de problemas etc. Assim, a autora afirma que o processo de inserção das TIC no ensino não consiste apenas em "alfabetização digital", mas sim em inovação no processo de ensino.

Kensky (2007) salienta que somente quando as TIC forem compreendidas e incorporadas pedagogicamente nos processos formativos é que contribuirão com alterações significativas no processo educativo.

Já Pretto e Rício (2010) abordam questões relativas à formação continuada de professores, tendo em vista o crescente uso das TIC no ensino e a expansão de cursos oferecidos à distância no Brasil. Salientam a importância das tecnologias digitais em redes, entendidas como "estruturantes de novas práticas comunicacionais, de formação e aprendizagem” (idem, p. 153), bem como indicam 
a necessidade de constituição de políticas públicas que visem à democratização do acesso a essas tecnologias.

\section{CONSIDERAÇÕES FINAIS}

A análise das pesquisas indica que, devido às mudanças e aos avanços tecnológicos que ocorreram na sociedade contemporânea, existe atualmente a necessidade de se repensar os processos de formação de professores, onde os usos de recursos das TIC estão sendo entendidos como mediadores em atividades de construção do conhecimento. Além disso, essa inclusão, que deve ser adequada às necessidades da sociedade contemporânea, se constitui num desafio e numa possibilidade de aproximação, entre ambientes escolares e realidades vivenciadas pelos estudantes, as quais estão impregnadas de tecnologias e de rápidos avanços tecnológicos.

A realidade atual é que o ensino tradicional já não consegue atender as necessidades dos estudantes, que pensam, processam e aprendem de maneira completamente diferente da geração que os antecedem, devido à inserção das TIC em suas vidas cotidianas, desde a mais tenra infância. Conforme D’Ambrósio (2008, p. 80):

A escola não se justifica pela apresentação de conhecimentos obsoletos e ultrapassados e muitas vezes morto, sobretudo ao se falar em ciência e tecnologia. Será essencial para a escola estimular a aquisição, a organização, a geração e a difusão do conhecimento vivo, integrado nos valores e expectativas da sociedade. Isso será impossível de se atingir sem a ampla utilização de tecnologia na educação. Informática e comunicação dominarão a tecnologia educativa do futuro.

Esse contexto naturalmente remete à necessidade da inserção das TIC em processos formativos de professores e em suas práticas, de modo a conscientizá-los, despertando seus interesses e motivando-os ao uso dos recursos apropriados de TIC, além de instrumentalizá-los para aturarem com inovações tecnológicas.

Os autores consultados indicam que não se trata apenas de utilização das TIC como ferramentas, mas que existe a necessidade de um redimensionamento no ensino, que implica em inovação de processos formativos e de práticas, de modo a explorar os recursos tecnológicos disponíveis, visando a valorização da autoaprendizagem e da virtualização do ensino. 
De acordo com Kampff:

As tecnologias, [...] ampliam o potencial humano. Todos reconhecem o papel fundamental das instituições escolares no desenvolvimento intelectual, social e afetivo do indivíduo. [...] cabe à escola incorporar em seu trabalho, apoiado na oralidade e na escrita, outras formas de aprender, [...] com uma tecnologia cada vez mais avançada. Mais do que resistir, é preciso desvendá-la e, conscientemente fazer uso dela (KAMPFF, 2006, p. 11-12).

Desse modo, é preciso pensar e propor práticas reflexivas em processos formativos, que possibilitem a construção de conhecimentos por meio da interação entre professores e estudantes, em ambientes de aprendizagem colaborativos, valorizando o aprender a aprender. Deste modo, o papel do professor, em processos formativos, deve ser repensado de modo que seja incentivado a ser mediador em atividades de conhecer. Segundo D'Ambrosio (2008, p. 79-80):

Não há dúvida quanto à importância do professor no processo educativo. Fala-se e propõe-se tanto educação a distância quanto outras utilizações de tecnologia na educação, mas nada substitui o professor. Todos esses serão meios auxiliares para o professor. Mas o professor, incapaz de utilizar desses meios, não terá espaço na educação. O professor que insistir no seu papel de fonte e transmissor de conhecimento está fadado a ser dispensado pelos alunos, pela escola e pela sociedade em geral.

Assim, as práticas devem ser elaboradas propondo inicialmente questionamentos próximos às realidades vivenciadas pelos estudantes, o que possibilitará um trabalho dialógico em sala de aula, favorecendo a autonomia e a necessidade de realizar esforço construtivo por parte do aluno, na construção de seu próprio conhecimento.

Assim como as pesquisas apresentadas, acreditamos que, ainda, é necessário o desenvolvimento de políticas públicas que possibilitem o acesso democrático às tecnologias, bem como o desenvolvimento de pesquisas voltadas para o futuro da educação, possibilitando repensar os rumos dos processos formativos dos professores, a fim de que estes desafios possam ser superados, de modo que as TIC sejam parte integrante natural do processo de ensino e de aprendizagem. 
Para que esta mudança ocorra, nos ambientes de aprendizagem, será necessário mudar a forma de pensar e de agir em processos formativos. Somente após serem pensadas e implantadas possibilidades adequadas de incorporação do uso de TIC em processos de ensino e de aprendizagem, será possível perceber transformações da realidade escolar em geral. Deve ser fruto de uma mudança efetiva na formação inicial e continuada dos professores, adequada às atuais necessidades da sociedade em que vivemos. Perrenoud (2000, p.128) afirma:

Formar para as novas tecnologias é formar o julgamento, o senso crítico, o pensamento hipotético e dedutivo, as faculdades de observação e de pesquisa, a imaginação, a capacidade de memorizar e classificar, a leitura e a análise de textos e de imagens, a representação de redes de procedimentos e de estratégias de comunicação.

E talvez seja esse o maior desafio da educação na atualidade: formar professores capazes de explorar os recursos tecnológicos que favoreçam a aprendizagem, de modo a potencializar a formação integral do estudante.

\section{REFERÊNCIAS}

BARRETO, R. G.; GUIMARÃES, G. C.; MAGALHÃES, L. K. C. AND LEHER, E. M. T. As tecnologias da informação e da comunicação na formação de professores. Revista Brasileira de Educação, Rio de Janeiro, vol. 11, n. 31, p. 31-42, 2006.

BRASIL. Secretaria de Educação Fundamental/MEC. Brasília, 2002. Disponível em: <dominiopublico.gov.br/download/ texto/me000511.pdf>. Acesso em: 19 mar. 2016.

D’AMBROSIO, U. Educação matemática da teoria à prática. 16.ed. Campinas: Papirus, 2008.

NÓVOA, A. Educación 2021: para una historia del futuro. Rev. Iberoamericana de Educación, n. 49, p. 181-199, 2009a.

2009b.

. Para una formación de profesores construida dentro de la profesión. Revista de Educación, n. 350, 203-218,

KAMPFF, A. J. C. Tecnologia da informática e comunicação na educação. Curitiba: IESDE Brasil S.A., 2006. 144 p.

KENSKY, V. M. Educação tecnologias: o novo ritmo da informação. Campinas: Papirus, 2007.

LÉVY, P. As tecnologias da inteligência: o futuro do pensamento na era da informática. Rio de Janeiro: Ed. $34,1993$.

MARTINI, C. M.; BUENO, J. L. P. O desafio das tecnologias de informação e comunicação na formação inicial dos professores de matemática. Educação Matemática Pesquisa, São Paulo, vol. 16, n. 2, p. 385-406, 2014.

OLIVEIRA, E. S. G. Indicativos para a formação continuada de professores incentivadora da apropriação das tecnologias. Múltiplas Leituras, vol. 4, n. 1, p. 99-114. 2011. 


\section{Kripka, Viali e Lahm, 2016 - Formação de Professores}

PERRENOUD, P. Formar professores em contextos sociais em mudança: prática reflexiva e participação crítica. Revista Brasileira de Educação, n. 12, p. 5-21, set.-dez. 1999.

. Dez novas competências para ensinar. Porto alegre/RS: Artes Médicas Sul, 2000.

PRETTO, N. L. Uma Escola com/sem futuro. Campinas: Papirus, 1996.

RICCIO, N. C. R.. A formação continuada de professores universitários e as tecnologias digitais. Educar, Curitiba, n. 37, p. 153-169, maio/ago. 2010.

SOUZA, W.; DUCATTI-SILVA, K.C. Formação continuada de professores do ensino fundamental: possibilidades de práticas inovadoras no ensino de matemática? Em: $\mathbf{O}$ professor PDE e os desafios da escola pública paranaense. Volume I. Secretaria da Educação - Governo do Paraná, 2012.

WELLS, G. Indagación dialógica: hacia uma teoria y uma práctica socioculturales de la educación. Buenos Aires: Paidós, 2001. 